\title{
A CONTRIBUIÇÃO DE DANIEL LIBESKIND PARA A CAPITAL EUROPEIA DA CULTURA
}

\author{
Juliana Barreto da Silva, Korina Aparecida Teixeira Ferreira Da Costa
}

Universidade do Oeste Paulista - UNOESTE, Curso de Arquitetura e Urbanismo, Presidente Prudente, SP. Email:barretojuliana@live.com

\section{RESUMO}

A presente pesquisa visa contextualizar a condição da contemporaneidade na arquitetura com ênfase no desconstrutivismo, a forma como é concebido e suas características fundamentais no avanço da arquitetura, em âmbitos tecnológicos, sociais e culturais. Tal vertente, vista como uma maneira de desafiar a natureza e provocar sentimentos e sentidos a partir da experiência humana no espaço, rompe com o tradicional empregado até então. A partir disto, exemplificando por meio de análises e concepções sobre a produção do arquiteto Daniel Libeskind, enfatiza a construção de um Centro Cultural na Bélgica, os direcionamentos desconstrutivistas empregados por tal e sua preocupação com o todo, partindo das premissas históricas e englobando a cultura, a memória e o significado, respeitando as condições pré-existentes e as necessidades sociais e políticas, sempre de forma sustentável.

Palavras-chave: Daniel Libeskind, arquitetura contemporânea, Bélgica, desconstrutivismo, cultura

\section{DANIEL LIBESKIND'S CONTRIBUTION TO THE EUROPEAN CAPITAL OF CULTURE}

\begin{abstract}
The present research aims to contextualize the condition of contemporary architecture with an emphasis on deconstructivism, your conception and its fundamental characteristics in the advancement of architecture, in a technological, social and cultural field. Such strand, seen as a way to defy nature and cause feelings and senses from the human experience in space, breaks with the traditional practiced until then. From this, exemplify by means of analyses and conceptions about the production of the Architect Daniel Libeskind, emphasizes the construction of a Cultural Centre in Belgium, the deconstructivist targeting employed by such and your concern for all, starting from the historical premises and encompassing culture, memory and meaning, respecting the pre-existing conditions and the social and political needs, always in a sustainable way.
\end{abstract}

Keyworks: Daniel Libeskind, contemporary architecture, Belgium, deconstructivism, culture 


\section{INTRODUÇÃO}

A condição contemporânea da arquitetura cria vertentes e debates desde a década de 1990, quando ela começou a ser repensada em controversa aos movimentos anteriores, principalmente no que se refere a produção pós-moderna, considerada irrelevante na busca de uma linguagem arquitetônica formal.

A renovação e o rompimento com a tradição deram espaço ao surgimento de diversas correntes, como a arquitetura desconstrutivista, representada por arquitetos como Rem Koolhaas e Zaha Hadid, o organicismo que caracteriza as obras de Frank Gehry e a arquitetura baseada na memória, nos monumentos e no contexto urbano, seguida pelo arquiteto Rafael Moneo.

Nas últimas décadas, continua perdurando a vertente da arquitetura que coloca em primeiro lugar sua própria história e a inserção urbana das obras. Assim como a importância outorgada aos sentidos, à percepção e à experiência humana, que surge como uma novidade, mas que se torna parte essencial para que essas novas ideologias resultassem no equilíbrio entre as novas formas contemporâneas, a revalorização do existente e a qualidade da cidade, do meio ambiente e da vida do usuário.

Dentro deste contexto, destaca-se o trabalho de Daniel Libeskind. Conhecido pela sua capacidade de evocar a memória cultural nos edifícios com o objetivo de criar uma arquitetura ressonante, única e sustentável, e sobre o qual discorrerá o presente trabalho, partindo da análise de sua posição quanto à forma de produzir arquitetura em nosso cenário atual e a tradução dessa posição na concepção de suas obras, com ênfase na sua contribuição para o projeto de um Centro Cultural na cidade de Mons.

\section{METODOLOGIA}

Esta pesquisa se deu através de embasamento teórico e análises, resultando em um levantamento histórico e analítico dos aspectos desconstrutivistas empregados pelo arquiteto Daniel Libeskind, com ênfase em uma de suas obras.

Para isto foram utilizadas bases de dados digitais e levantamento de referenciais teóricos específicos, como Robert Venturi, Peter Eisenman e Jacques Derrida, contextualizando o panorama pós-moderno ao surgimento do termo descontrução. 0 estudo de caso ainda é composto por dados disponibilizados pelos próprios autores do projeto, em plataformas digitais oficiais, tais como: o site oficial do Studio Libeskind (www.libeskind.com) e o Archdaily (www.archdaily.com.br).

\section{RESULTADOS}

O cenário da arquitetura atual se abre para diversas vertentes de estudo, inovação e experimentação, cujos arquitetos citados e tantos outros, são responsáveis por romper com os ideais impostos pelo pós-modernismo, que valorizava a forma mais do que a função, chegando a considerar a função como algo exterior à arquitetura (VENTURI, 1966).

Uma dessas vertentes que só foi possível após a superação do pós-modernismo e os avanços tecnológicos foi o desconstrutivismo. Segundo Eisenmann (1976), a arquitetura desconstrutivista se empenha em despertar os sentidos. É a arquitetura do contraste, causadora e despertadora de sentimentos e sensações, tocando o emocional do ser, sendo cada qual com afeto diferente; rompendo com a racionalidade, sendo esse rompimento a base e a essência da situação vigente para iniciar algo dentro deste movimento.

Essa arquitetura ligada aos sentidos, à percepção e à experiência humana foi possível graças à conceitualização das teorias de alguns filósofos como Jacques Derrida. Esses 
conceitos ganharam extrema importância e podem ser vistos expressos na obra do arquiteto Daniel Libeskind, que possui forte ligação ao pensamento baseado nos estudos sobre desconstrução do filósofo (MONTANER, 2016; GOMES, 2012).

Derrida acreditava que traduzida, a palavra "desconstrução" poderia ser arquitetura, pois para ele o termo significava "não uma destruição, mas uma desestruturação que desmonta as camadas estruturais do sistema" (GOMES, 2012). Isso significaria "desmontar um edifício, para se entender como este é constituído ou desconstituído" (WIGLEY, 1995, p. 41 e 42).

Os edifícios influenciados por essa vertente podem ser vistos como uma simples junção abstrata de formas, sem lógica aparente, mas na realidade a coesão dessas formas é resultado da lógica presente nos princípios desconstrutivistas (GOMES, 2012). Neste sentido, podemos associar a desconstrução de um edifício ao rompimento da tradição, pois desconstruindo enxergamos e relacionamos todos os elementos a uma única complexidade resultante no entendimento total da questão, e não de forma independente.

Com base neste referencial teórico contextualizado, o presente trabalho pôde apresentar as características e aspectos da contemporaneidade do desconstrutivismo, juntamente com o rompimento do tradicional e as raízes deixadas no contexto que envolve a obra do arquiteto Daniel Libeskind.

\title{
DISCUSSÃO \\ DANIEL LIBESKIND
}

Segundo Gomes (2012), Daniel Libeskind nasceu em 1946 em Lódz, na Polónia e emigrou com a sua família para os Estados Unidos da América e em 1964. Libeskind teve um percurso interessante até concretizar sua carreira, estudou música em Israel e Nova lorque. Abandonou o estudo da música para estudar arquitetura e formou-se em 1970 na Cooper Union for the Advancement of Science and Art in New York City. Foi-lhe ainda atribuído um título de pós-graduação em História e Teoria da Arquitetura na School of Comparative Studies na Universidade de Essex, em 1972.

Em 1989, Daniel e sua parceira Nina Libeskind estabeleceram o Studio Libeskind em Berlim, na Alemanha, depois de vencerem a competição para construir o Museu Judaico de Berlim, dedicando mais de uma década à construção da obra. O volume é baseado na desconstrução da estrela de Davi, símbolo judeu. Segundo Andrew Kroll (2010), o projeto é uma das construções mais emblemáticas que retratam o holocausto, do qual os próprios pais do arquiteto foram sobreviventes. É um edifício cheio de simbolismo, que dispõe aos seus visitantes uma intensa viagem cheia de emoções e sensações por seus corredores.

Segundo Gomes (2012) Libeskind desde cedo se identificou com a corrente desconstrutivista e, por diversas vezes, sua arquitetura foi taxada como polêmica, como pode ser visto em algumas de suas principais obras: o Royal Ontario Museum, a casa 18.36.54 ou o Museu de História Militar. Apesar disso tinha um pensamento muito realista, como afirma em entrevista:

\begin{abstract}
A arquitetura é como contar uma história. Eu vejo isto como uma história acerca de uma cidade e o futuro: não sobre técnicas e eletricidade. Desenhar um edifício é como produzir uma peça musical. Deve ser coreografada e interpretada por outras pessoas, senão é uma coisa morta. (The Sunday Times, 2005).
\end{abstract}

Em 2003, o Studio Libeskind ganhou outra competição histórica - a reconstrução do World Trade Center em Lower Manhattan. Ele propôs um programa complexo que está sendo realizado até hoje (LIBESKIND, 2017). 
O arquiteto explica na introdução do seu livro "The Space of Encounter" que o seu trabalho "desenvolveu-se em direções inesperadas através de uma prática que não imita procedimentos pré-existentes, mas que tenta evidenciar-se pela emoção, aventura e mistério da arquitetura, deixando de parte os conceitos de "forma", "função" e programa, envolvendo-se na realidade pública e política que é sinônimo de arquitetura" (LIBESKIND, 2001, p.17).

Segundo conta em seu site, Daniel abriu o Studio Libeskind em Milão (atualmente a sede encontra-se em Nova lorque), no ano de 2012. Além de novos projetos arquitetônicos, o Studio desenvolveu um departamento de design industrial, de produtos e de interiores. Foi neste mesmo período que desenvolveu o projeto para o Centro de Convenções do Congresso Internacional da cidade de Mons, na Bélgica, que viria a ser a Capital Europeia da Cultura em 2015.

\section{O CENTRO DE CONVENÇÕES DO CONGRESSO INTERNACIONAL DE MONS}

O Centro de Convenções do Congresso Internacional de Mons é um centro cultural situado na Cidade de Mons, Bélgica e foi projetado pelo arquiteto Daniel Libeskind e sua equipe, em conjunto com o H2a Arquitetos Associados. Segundo informações encontradas nas plataformas digitais dos autores do projeto, a construção teve início no ano de 2012 e foi concluída em 2015, ano da sua inauguração e mesmo ano em que a cidade de Mons foi promovida a Capital Europeia da Cultura.

A Capital Europeia da Cultura é uma iniciativa da União Europeia lançada em 1985 que tem por objetivo a promoção de uma cidade da Europa, por um período de um ano, durante o qual a cidade possui a hipótese de mostrar à Europa sua vida e desenvolvimento cultural, valorizando a riqueza e a diversidade das culturas europeias, assim como suas características comuns e contribuindo para um maior conhecimento mútuo entre os cidadãos da União Europeia (EUROCID, 2017).

Em 2015, a cidade de Mons foi nomeada a Capital Europeia da Cultura, e concebeu o Centro do Congresso como seu novo marco arquitetônico, um elemento-chave no plano de revitalização econômica da cidade, que seria um conector entre o antigo e o novo. A partir da plataforma de visualização no topo do edifício, um visitante pode espionar a torre Beffroi do século XVII, Patrimônio da UNESCO da Bélgica, no centro histórico da cidade, e uma nova estação ferroviária desenhada por Santiago Calatrava no bairro mais novo de "Grands Prés" (LIBESKIND; SOLKOFF, 2015). A apreciação da paisagem estaria completa com as vistas para o Rio La Haine. Essa relação com a paisagem, o contraste entre o novo e o antigo e o resgate da memória reafirma sua metodologia de projeto, baseada em uma arquitetura que deve ser sentida e interpretada pelas pessoas.

\section{RELAÇÃO DE FORMA, FUNÇÃO E ESTRUTURA}

O centro é uma expressão de formas geométricas contrastantes. Totalizando uma área de $12.500 \mathrm{~m}^{2}$, ele abriga um grande hall de entrada, três auditórios de tamanhos variados, um salão polivalente, salas de conferências, escritórios, um restaurante, um estacionamento subterrâneo e um terraço público (SOLKOFF, 2015). O emprego desses espaços flexíveis, abertos e coletivos se abre para uma relação total e desimpedida entre espaço e o usuário, que circula pelo edifício, apropriando-se e aproveitando todas as sensações aguçadas por sua materialidade incomum. 
O projeto também busca soluções da arquitetura bioclimática, resultando em um edifício altamente eficiente de energia, com telhado verde, sombreamento passivo, resfriamento noturno e placas fotovoltaicas (SOLKOFF, 2015).

Para mim, a construção sustentável não é uma nova tendência de design ou um recurso adicional, trata-se de sentido e de qualidade comum. Se você construir da maneira correta, utilizando materiais de alta qualidade, inovação e tecnologia, você vai criar algo duradouro e sustentável. (The Sunday Times, 2005, trecho retirado de entrevista)

Para manter a integridade visual da forma, os arquitetos inseriram algumas janelas ao longo da parede de fita, cujas lâminas sobrepõem as janelas. Essas lâminas são giradas para permitir a entrada de luz solar e a permeabilidade visual com o entorno (LIBESKIND, 2015). O uso da tecnologia atrelada à sustentabilidade caracteriza a contemporaneidade presente na obra.

Segundo o arquiteto em texto disponibilizado ao ArchDaily (2015), o revestimento do Centro do Congresso está aberto de forma a dar textura e luz à estrutura composta por paredes de concreto de fita que sobem em uma espiral. As paredes inferiores estão revestidas de lâminas verticais de madeira robínia e a parte superior é revestida com bandas verticais de alumínio anodizado que seguem a curva da parede. As paredes permitem uma grande flexibilidade do espaço, e a madeira utilizada cria uma identidade com as árvores do parque vizinho, atrelando certo simbolismo local.

Ao redor do complexo é um pátio de concreto polido, de cor verde, ferrado com faixas de pedra azul da Bélgica. Essas bandas azuis continuam nas paredes da fita e no interior do edifício, formando um padrão irregular que reafirma a materialidade do projeto (LIBESKIND, 2017). No interior podemos observar a desconstrução do ponto de vista, característica presente na arquitetura desconstrutivista e que rompe com o tradicional "ponto-de-fuga", presente nas representações realistas do mundo desde o período renascentista.

Segundo Silvio Colin (2009), a perspectiva traz a ideia do ponto-de-vista único, que só é possível utilizando a perspectiva como ferramenta, porém o ponto de vista está ligado à ideia do "sujeito", que é a peça fundamental no projeto desconstrutivo, mas que não pode conviver com a ideia das estruturas que o antecedam, já que muitas vezes elas governam seus pensamentos e ações, o que seria contrário aos ideais da corrente. Os arquitetos desconstrutivistas trabalham com linhas e planos inclinados, explorando estruturas em posições aparentemente instáveis que representam a ideia de desafio da natureza, a incompletude, a imperfeição e o desequilíbrio das leis.

Os grandes planos esculturais da fachada são responsáveis por envolver o edifício e o espaço circundante dessa obra desafiadora, cheia de identidade e representatividade. Daniel Libeskind conseguia desafiar, mais uma vez, os princípios tradicionais, da natureza; atrelando a bela forma contemporânea à solução arquitetônica sustentável e adequada à atualidade.

\section{CONCLUSÃO}

Conclui-se que a produção arquitetônica contemporânea caracterizada pela fragmentação e interesse pela manipulação das superfícies das estruturas, das formas distorcidas e deslocadas, diferente de alguns dos princípios elementares da arquitetura, foram extremamente importantes para a idealização de uma nova arquitetura, que rompe com a tradição e abre diversos caminhos para o campo de estudo arquitetônico. 
Essas características, encontradas nos edifícios desconstrutivistas, atreladas ao avanço tecnológico, à busca por uma arquitetura sustentável e que considera conceitos préexistentes de lugar e memória das pessoas - indivíduos como precursores primários dessa arquitetura -, definem um projeto totalmente adequado às necessidades dos seus usuários, e que conseguimos identificar nas obras de Daniel Libeskind e em especial na obra estudada.

Sua forma de projetar é marcada não somente pelas características formais, da sua estrutura tão desafiadora, mas abordam o conjunto complexo, desconstruído e claro, que engloba a arquitetura como um todo social e político, mas de uma forma bela e impactante que possa ser absorvida pela humanidade.

\section{REFERÊNCIAS}

VENTURI, R. Complexidade e contradição em arquitetura: trechos selecionados de um livro em preparação (1966). p.91-95. NESBIT, Kate. Uma nova agenda para a arquitetura. São Paulo: Cosac Naify, 2008.

EISENMAN, P. O pós-funcionalismo (1976). p.95-101. NESBIT, Kate. Uma nova agenda para a arquitetura. São Paulo: Cosac Naify, 2008.

MONTANER, J. M. A condição contemporânea da arquitetura. São Paulo: Gustavo Gili, 2016.

GOMES, L. M. G. Daniel Libeskind e Steven Holl: estudo de duas obras e um projecto. Dissertação de mestrado integrado em Arquitectura, Universidade Lusíada de Lisboa, 2012.

WIGLEY, M. The Architecture of Deconstruction: Derrida's Haunt. London: MIT Press, 1997.

KROLL, A. "AD Classics: Jewish Museum, Berlin / Daniel Libeskind". 25 Nov 2010. ArchDaily. Disponível em: http://www.archdaily.com/91273/ad-classics-jewish-museum-berlin-daniellibeskind/. Acesso em 21/11/2017.

SOLKOFF, J. Mons International Congress Xperience. 5 mai 2015. Disponível em: $<$ https://www.e-architect.co.uk/belgium/mons-international-congress-xperience-inbelgium>. Acesso em: 21/11/2017

Texto fornecido pelos arquitetos. "Mons International Congress Xperience (MICX) / Studio Libeskind + H2a Architecte \& Associés". 07 Jan 2015. ArchDaily. Disponível em: $<$ https://www.archdaily.com/584678/mons-international-congress-xperience-micx-studiolibeskind-h2a-architecte-and-associes/. Acesso em 21/11/2017.

COLIN, S. Estruturalismo, pós-estruturalismo e arquitetura. Abril 2009. Revista AU Pini. Disponível em: <http://au17.pini.com.br/arquitetura-urbanismo/181/artigo131095-1.aspx>. Acesso em: 21/11/2017.

SITE OFICIAL DO STUDIO LIBESKIND. Disponível em: <www.libeskind.com>. Acesso em: 21/11/2017 